\title{
Health Risk Evaluation of Selected Heavy Metals in Infant Nutrition Formula in Cross River State, Nigeria
}

\author{
*AKPE, MA; UBUA, PU; IVARA, SE \\ Department of Pure and Applied Chemistry, Faculty of Science, University of Calabar, Calabar, Nigeria \\ *Corresponding Author Email: akomayeakpe2015@gmail.com
}

\begin{abstract}
The aim of this study is to ascertain the level of some heavy metals namely; Arsenic, Cadmium, Chromium, Cobalt and Lead in baby milk or infant formulas used in the country and evaluate the health risk associated with their consumption. Five (5) brands of popularly consumed and most preferred or recommended infant formula foods for children in Nigeria were bought from the main (Watt) market in Calabar, Cross River State, Nigeria and were coded and labeled $\mathrm{V}, \mathrm{W}, \mathrm{X}, \mathrm{Y}$ and $\mathrm{Z}$ respectively. The samples were digested in the fume cupboard using aqua regia and analyzed for heavy metals using Flame Atomic Absorption Spectrometer (AAS). The results showed that the concentration of Arsenic was less than $0.001 \mathrm{mgkg}^{-1}$ across all the five (5) brands. Cadmium concentration ranged between $0.010-0.052$ $\mathrm{mgkg}^{-1}$, and it was detected in all the samples. Cobalt ranged between $0.002-0.010 \mathrm{mgkg}^{-1}$, and it was detected in 3 out of the 5 samples. Chromium concentration ranged between $0.002-0.004 \mathrm{mgkg}^{-1}$ was detected in 4 out of the 5 samples or brands of infant formula studied. Lead amount ranged between $0.080-0.014 \mathrm{mgkg}^{-1}$ and was less than $0.001 \mathrm{mgkg}^{-1}$ in 2 brands out of the five brands sampled. These results are low and within the permissible limits of WHO. The Target Hazard Quotients (THQ) of these metals were all less than 1 except for Cadmium in brand V that was 1. This indicates that there is no health danger associated with the imgestion of the infant formulas at the moment.
\end{abstract}

\section{DOI:https://dx.doi.org/10.4314/jasem.v25i3.17}

Copyright: Copyright $(\odot 2021$ Akpe et al. This is an open access article distributed under the Creative Commons Attribution License (CCL), which permits unrestricted use, distribution, and reproduction in any medium, provided the original work is properly cited.

Dates: Received: 12 December 2020; Revised: 26 January 2021; Accepted: 12 February 2021

Keywords: Health risk, Heavy metals, Infant formula, Calabar-Nigeria

Infant formula is a breast-milk substitute specifically produced to meet the nutritional requirements of infants during the first few months of life before the introduction of necessary supplementary feeding. As a matter of fact, elements and ions may find route into foods as a result of processing, packaging, farming activities and industrial emissions (Ljung et al., 2011).As of 2011, the World Health Organization (WHO), United Nation Children's Fund (UNICEF) and many national health agencies recommended six months of age before starting a child on food. However, individual babies may differ greatly from this guideline based on their unique developmental progress. Humans are often exposed to heavy metals in various ways - mainly through the inhalation of metals in the workplace or polluted neighbourhoods, or through the ingestion of food (particularly seafood) that contains high levels of heavy metals or paint chips that contain lead. The three heavy metals commonly cited as being of the greatest public health concern are cadmium, lead, and mercury. There is no biological need for any of these three heavy metals (Anderson, et al., 2017).Milk is the perfect natural source of food for feeding infants as it contains the highest balance of proteins, fats and carbohydrates for developing babies. Unfortunately, pollution of human milk has become widespread. Polychlorinated biphenyls, DDT, dioxins and heavy metals are among the poisonous chemicals mostly found in breast milk (Sonawance, 1995). 'The level of exposure to chemical residues in human milk for breast-feeding children depends on mother's food ingestion patterns and the toxicological viability of those chemicals. For instance, calcium deficiency can increase the mobility of lead from mother's bone to enter her breast milk (Gulson et al., 1998)'.

Infant formulas have a wide gap to fill. They must mimic breast milk as much as possible. But it is difficult to produce a formula equal in all respects to breast milk (Gulson et al., 1998). 'Infant formula has been found to be polluted with toxic metals, bacteria, and other environmental contaminants. It may contain high levels of metals like aluminum, cadmium, lead and manganese. An infant's exposure to cadmium from soya infant formula is about 20 times higher than the amount usually found in breast milk' (Oskarsson, 1995).There is a rising concern about the quality and safety of foods in different parts of the globe. 'Contaminated sources of ingredients and adulteration of food for economic reasons necessitate the need for accurate, sensitive and precise analytical procedures for the presence of $(\mathrm{As}, \mathrm{Cd}, \mathrm{Hg}$ and $\mathrm{Pb}$ ) toxic heavy 
metals' (Hanlon et al., 2015).The effect of environmental pollution on contamination of foods and on their safety for human consumption is a serious global public issue and widely addressed (Alegeria et al., 1990). Metals such as lead, mercury, cadmium, and copper are cumulative poisons, which cause environmental hazards and are reported to be exceptionally toxic (Gopalani et al., 2007). On consumption of food in the diet, the trace metal contents of food are directly taken into the body (Gulson et al., 1998). Metals pollution as a result of increasing industrialization has penetrated into all sectors of the food industry and as such pose fears for infant formula milk (Gian et al., 2009).It has been scientifically established from research that breast milk is the best and richest food for the infant during the early stage of life between 0 to 6 months, as it contains all the nutrients and immunological factors an infant needs to maintain good health and proper growth. Furthermore, 'breast milk also shields infants against the two major causes of infant mortality, upper respiratory infections and diarrhea. However, at the age of six months and above when the child's birth weight is expected to have doubled, breast milk is no longer enough to meet the nutritional requirements of the growing infant' (WHO,1998). 'Breastfeeding is the best mode of nutrition for infants. However, commercially available infant formulas provide a suitable alternative, especially when breastfeeding is not possible and or not adequate' (Motil, 2000). 'Nutritious complementary foods are often introduced which are also called weaning foods between the period of six to twenty four months of age in most developing countries' (Nigerian Nutrition Network (NNN), 2002).

Heavy metals are natural components of the Earth's crust, persistent in all parts of the environment and cannot be degraded or destroyed. They enter the human body through drinking water, food and air in small levels. According to Duffus (2002), a heavy metal is a collective term, which refers to the group of trace metals and metalloids with and atomic density greater than $4 \mathrm{~g} / \mathrm{cm}^{3}$. Living organisms need varying amounts of heavy metals and certain amounts of iron, copper, cobalt, manganese, molybdenum, and zinc are needed by humans. However, some heavy metals like lead and mercury are poisonous metals that have no vital role to play in organisms, and their presence over time in animals can lead to serious disease. Some elements, called trace elements or micronutrients, have important roles in plant and animal cells. This has been shown for $\mathrm{Fe}, \mathrm{Co}, \mathrm{Cu}, \mathrm{Mo}, \mathrm{Mn}, \mathrm{Ni}$ and $\mathrm{Zn}$. It is when their internal amount becomes higher than a certain permissible concentration that they manifest toxic effects, and then they are commonly termed "heavy metals" (Khalifa and Ahmad, 2010). Metals and their compounds can accumulate in the body's tissues, such as bones or nerves. Children are the most susceptible to health problems caused by heavy metals, because their bodies are smaller and still developing. Parween et al. (2016) stated that "minerals and heavy metals are naturally present in milk and foodstuffs, yet they can still come into milk and food through anthropogenic routes such as transport, industry, power generation and refuse burning'. The health dangers posed by heavy metals depend on the amount and the length of exposure. In some instances, the health effects are instantly visible; in others, the effects are spontaneous. 'High doses of toxic metals accumulated in body tissues and subsequently in the brain, may cause developmental and neurological damage, such as depression, insomnia, hallucination, memory loss, anxiety, aggression and many other disorders' (Thomson and Pacquett, 2015).

Despite the benefits of infant formula as a major source of food for infants, the presence of contaminants, such as heavy metals, pesticides and polychlorinated biphenyls (PCBs) in infant formula may pose health risks to children(Abua et al., 2002). It has been reported that children are more susceptible to exposure because of their greater intestinal absorption than adults, and a lower threshold for adverse effects. These pollutants may arise from the raw materials used in production, poor quality production processes, adulteration of infant foods and bad practices by mothers as regards infant formulation preparation and handling (Abua et al., 2002).Infants are exposed to heavy metals through breast milk, infant formula and complementary foods. Consequently, there is need for continued monitoring of heavy metals in food and in the environment with special attention being paid to critical analysis of the quantity of heavy metals present in them. Infants are a special, crucial and sensitive population to every nation and Nigeria is not an exception. Their small mass and developing systems/ brain may manifest harsh health effects from even low levels of pollution on a single dose. Hence, this study is centered on heavy metals assessment of infant nutrition formula used in Nigeria.

Several researches have been undertaken in different countries of the globe like USA, United Kingdom, and Saudi Arabia on the amount of heavy metals in infant formula or baby milk as cited in this study to ascertain the level of these metals in baby food and the possible exposure of children to these metals with the view of safeguarding the health of their children and their countries. However, this seems to be lacking in Nigeria and it is the main reason or aim why this study 
was conceived and undertaken to ascertain the level of some these heavy metals in baby milk or infant formula used in the country and assess the health risk associated with their consumption. Besides, due to non-exclusive breast feeding and its replacement by infant formula food nowadays, it is expedient to ascertain the heavy metals composition of baby foods because of their harmful or toxic nature. The objective this study therefore is to determine some heavy metals concentration of some baby foods or infant formula foods marketed and consumed in Nigeria.

\section{MATERIALS AND METHODS}

Sample Collection and Preparation: Five (5) brands of popularly consumed and most preferred or recommended infant formula foods for children in Nigeria were bought from the main (Watt) market in Calabar, Cross River State, Nigeria and taken to Chemistry Department Laboratory, University of Calabar, for pre-treatment and heavy metals analysis. The samples were coded and labeled V, W, X, Y and $Z$ respectively.

Samples Digestion: the samples were digested following one of the procedures for sample preparation for heavy metals analysis in line with the methods of the Association of Official Analytical Chemists (AOAC) as follows: '2.0 $\mathrm{g}$ of each sample (infant formula) powder was weighed into a clean dry beaker in a fume cupboard. $20 \mathrm{~mL}$ of aqua regia (mixture of concentrated $\mathrm{HCl}$ and $\mathrm{HNO}_{3}$, in the ratio $3: 1)$ was added to the sample in the beaker'. The beaker was covered with a clean dry watch glass and heated at $90{ }^{\circ} \mathrm{C}$ for about 2 hours; the beaker was removed, allowed to cool, washed together with the watch glass using de-ionized water into a volumetric flask and made-up to $100 \mathrm{~mL}$ solution. The solution was filtered and supernatant liquid solution was used for heavy metal analysis.

Element Analysis: the samples were analyzed for As, $\mathrm{Cd}, \mathrm{Co}, \mathrm{Cr}$ and $\mathrm{Pb}$ using a VGP 210 BUCK ScientificModel of flame Atomic Absorption Spectrometer (AAS) (Akpe and Ubua, 2019; Akpe et al. 2019a).

Calculations:The Target Hazard Quotient is the ratio of the body intake dose of a pollutant to the oral reference dose and it is calculated as follows:

$$
T H Q=\frac{D I V x C m}{R f D x B}
$$

Where DIV is the daily intake of vegetable in $\mathrm{kg} / \mathrm{day}$, $\mathrm{Cm}$ is the concentration of pollutant (heavy metal) in the vegetable in $\mathrm{mgkg}^{-1}, \mathrm{~B}$ is the average body weight of humans in $\mathrm{kg}$, while $\mathrm{R}_{\mathrm{f}} \mathrm{D}$ is the oral reference dose of the pollutant permissible and it is fixed by United States Environmental Protection Agency (US-EPA) (Akpe et al., 2019b). Note: B was assumed for this study to be $5 \mathrm{~kg}$ for all infant children, while the DIV was assumed to be $100 \mathrm{~g}(0.1 \mathrm{~kg} /$ day $)$ per day. From the formula, THQ is a dimensionless parameter or ratio. According to US-EPA through Integrated Risk Information System-database IRIS (2011), 'if THQ is less than $1(\mathrm{THQ}<1)$, it shows that there is no potential health risk associated with the pollutant. But if THQ $>1$, there is a health risk associated with the pollutant (heavy metal) at that moment.' The RfD values for $\mathrm{Cd}, \mathrm{Co}, \mathrm{Cr}$ and Pbfrom IRIS are 0.001, 0.1, 0.003 and $0.0035 \mathrm{mgkg}^{-1}$ respectively IRIS (2011).

\section{RESULT AND DISCUSSION}

The results of the analysis are presented in Tables 1 and 2 for the concentration of the heavy metals in the samples (Infant formula foods) and their corresponding Target Hazard Quotients respectively; and discussed.The results in Table 1above revealed that the concentration of Arsenic was less than 0.001 $\mathrm{mgkg}^{-1}$ across all the five (5) brands sampled. This implies that its amount in the infant formula brands is insignificant and negligible at the moment. Cadmium concentration ranged between $0.010-0.052 \mathrm{mgkg}^{-1}$, and it was detected in all the samples. Cobalt ranged between $0.002-0.010 \mathrm{mgkg}^{-1}$, and it was detected in 3 out of the 5 samples. Chromium was detected in 4 out of the 5 samples or brands of infant formula considered, and its concentration ranged between $0.002-0.004 \mathrm{mgkg}^{-1}$. Lead was less than 0.001 in 2 brands and greater than 0.001 in three out of the five brands sampled, and its amount ranged between 0.080 $-0.014 \mathrm{mgkg}^{-1}$. From the results, the concentration of the heavy metals studied across the 5 brands of infant formula was in the order: Cadmium $>$ Lead $>$ Cobalt $>$ Chromium > Arsenic. These results are low and within the permissible limits of the World Health Organization (WHO). The results also agree with a related study in USA, UK and Nigeria by Abua et al. (2002) where it was reported that $\mathrm{Cd}, \mathrm{Pb}, \mathrm{Ni}$ and $\mathrm{Cr}$ levels in some milk brands in Nigeria were below FAO/WHO recommended provisional tolerable weekly intakes and their respective limits for drinking water. Gaw (2006) have stated that a study by the Food Standards Agency in the United Kingdom in 2006 , revealed that the average concentration of Arsenic in various brands of baby milk is up to $0.1 \mathrm{ppm}$. Also, Lead concentration in infant formula used for this study are lower than those reported by Lanphear et al. (2008) for children's milk in Iran and Saudi Arabia by Khalifa and Ahmed (2010) which are $(0.384 \pm 0.22)$ and $(0.018 \pm 0.02) \mathrm{ppm}$ respectively. 


\begin{tabular}{llllll}
\multicolumn{6}{c}{ Table 1: Heavy metals concentration in selected infant formula foods in Nigeria in $\mathrm{mgkg}^{-1}$} \\
\hline Sample & $\mathbf{A s}$ & $\mathbf{C d}$ & $\mathbf{C o}$ & $\mathbf{C r}$ & $\mathbf{P b}$ \\
ID & & & & & \\
\hline $\mathbf{V}$ & $<0.001$ & $0.052 \pm 0.010$ & $0.010 \pm 0.002$ & $0.004 \pm 0.001$ & $0.080 \pm 0.012$ \\
$\mathbf{W}$ & $<0.001$ & $0.010 \pm 0.002$ & $<0.001$ & $0.002 \pm 0.001$ & $<0.001$ \\
$\mathbf{X}$ & $<0.001$ & $0.046 \pm 0.010$ & $0.002 \pm 0.001$ & $0.004 \pm 0.001$ & $0.012 \pm 0.002$ \\
$\mathbf{Y}$ & $<0.001$ & $0.018 \pm 0.005$ & $<0.001$ & $0.002 \pm 0.001$ & $<0.001$ \\
$\mathbf{Z}$ & $<0.001$ & $0.032 \pm 0.008$ & $0.002 \pm 0.001$ & $<0.001$ & $0.014 \pm 0.002$ \\
\hline \multicolumn{6}{c}{ Note: Values reported in Mean + Standard deviation with $N=3$}
\end{tabular}

Table 2: Target Hazard Quotients some Heavy metals in selected Infant formula foods in Nigeria

\begin{tabular}{llllll}
\hline $\begin{array}{l}\text { Sample } \\
\text { ID }\end{array}$ & As & Cd & Co & Cr & Pb \\
\hline $\mathbf{V}$ & Nil & 1.040 & 0.0020 & 0.027 & 0.457 \\
$\mathbf{W}$ & Nil & 0.200 & Nil & 0.013 & Nil \\
$\mathbf{X}$ & Nil & 0.920 & 0.0004 & 0.027 & 0.069 \\
$\mathbf{Y}$ & Nil & 0.360 & Nil & 0.013 & Nil \\
$\mathbf{Z}$ & Nil & 0.640 & 0.0004 & Nil & 0.080 \\
\hline
\end{tabular}

The Target Hazard Quotients (THQ) of these metals as shown in Table 2 was all less than 1 except for Cadmium in brand $\mathrm{V}$ that was 1 .This indicates that there is no health danger associated with the ingestion of this infant formula at the time this study was undertaken. THQ values of less than 1 portrays that no health risk is associated with a particular food pollutant, while values greater than 1 portrays that there is health risk associated with the pollutant or contaminant. When its value(s) is equal to 1 which is the threshold value, serious and effective monitoring and control is required to reduce the amount of such pollutants or contaminants in the given food sample.

Conclusion: The findings of this study revealed that infant formula food(s) or milk often used in Nigeria in place of breast milk when it is not available, especially in the absence of the mother due to death after child birth or abandonment among other reasons contains some level of heavy metals. However their heavy metal concentration is low and may not pose a health risk to the infant's population for now. Thus, there is need to ascertain the quality of this infant formula food(s) in Nigeria regularly.

Acknowledgement: The authors appreciate the contributions of Ms. Chris- Isaac Utomobong towards the success of this study.

\section{REFERENCES}

Abua, I; Alwell, N; Seyi, O; Kafui, N; Nosa, E (2002). Levels of 26 elements in infant formula from USA, UK and Nigeria by microwave digestion and ICP-OES. Food Chem., 77(4):439-447

Akpe, MA; Ubua, PU (2019). Concentration of heavy metals ( $\mathrm{Cd}, \mathrm{Co}, \mathrm{Cr} \& \mathrm{Fe})$ in soil and edible vegetables in Obudu Urban Area of Cross River
State, Nigeria. Chem. Sci. Inter. J., 2019; 27(1):17

Akpe, MA; Odey, J; Agwupuye, JA (2019a). Concentration of selected heavy metals in soil and edible vegetables in Obanliku Urban Area of Cross River State, Nigeria. J. Sci. Res. Reports, 24(6):1-8

Akpe, MA; Ashishie, PB; Inezi, FP (2019b). Health risk assessment of heavy metals $(\mathrm{Cr}, \mathrm{Fe}, \mathrm{Hg} \& \mathrm{Ni})$ in edible vegetables in Yala urban area, Cross River State, Nigeria. Intern. Res. J. of Pure \& Appl. Chem. 19(2): 1-7

Alegeria, A; Barbera, R; Fare, R (1990). Influence of environmental contamination on $\mathrm{Cd}, \mathrm{Co}, \mathrm{Cr}, \mathrm{Cu}$, $\mathrm{Ni}, \mathrm{Pb}$ and $\mathrm{Zn}$ content of edible vegetables, safety and nutrition aspects. J. of Micronutr. Anal. 8:91104

Anderson, JW; Johntone, BM; Ranley, DT (1997). Breastfeeding and cognitive development: a meta-analysis. Amer. J. Clin. Nutr. 70(4):525-535

Duffus, JH (2002). Heavy metal- a meaningless term? IUPAC Technical Report. Pure and Appl. Chem. 74:798-807

Gaw, K; Wilkins, A; Kim, N; Palmer, G; Robinson, P (2006). Trace elements and DDT concentrations in horticultural trial soils from the Tasman, Waikato and Auckland regions of New Zealand. Sci. Total Environ. 35(5):31-47

Gian, C; Zaheer, D; Christian, D; Angela, M; Eva, M; Hanna, M; Margot, E; Jennifer, W (2009). Analysis of toxic heavy metals in selected infant 
formula milk commercially available in Philippines by AAS. E-Int. Sci. Res. J. 1:40-51

Gopalani, M; Shahare, M; Ramteke, DS (2007). Heavy metal contents of potato chips and biscuits from Nagpur City, India. Bull. Environ. Contamin. Toxicol. 79:384-387

Gulson, BL; Jameson, CW; Mahaffey, KB; Mizon, $\mathrm{KJ}$; Korsch, MJ; Cameron, MA; Eisman, JA (1998). Mobilization of Lead from the skeleton during the postnatal period is larger than during pregnancy. J. Lab. Clinical Med. 13:324-329

Hanlon, PR; Hlywka, JJ; Scimecca, JA (2015). Food Protect. Trends. 35:89-100.

IRIS (2011). Integrated Risk Information System Database. US Environmental Protection Agency (US-EPA).

Khalifa, A; Ahmad, D (2010). Determination of key elements by ICP-OES in commercially available infant formula and baby foods in Saudi Arabia. Afri. J. of Food Sci., 4:464-468.

Lanphear, B; Dietrich, K; Auinger, P; Christopher, C (2008). Cognitive deficit associated with blood lead concentrations less than ten micrograms deciliter in US children and adolescents. Publ. Health Reports, 4:87-96.
Ljung, K; Palma, B; Grander, M; Vahter, M (2011). High concentrations of essential toxic elements in infant formula foods - a matter of concern. Food Chem. J., 40:1-9.

Motil, KJ (2000). Infant feeding: a critical look at infant formulas. Curr. Opin. Pediatric. 12:469476.

Nigerian Nutrition Network (NNN), (2002). Communique and papers presented at the $1^{\text {st }}$ Annual NNN meeting, Abeokuta, Nigeria, pp.1213.

Oskarsson, A; Hallen, IP; Sundberg, J (1995). Exposure to toxic elements via breast milk. Analyst, 120:765-770.

Parween, R; Shankat, SS; Yasmeen, K; Ara, D (2016). Evaluation of environmental impact on heavy metals load in cattle milk. Pol. J. of Environ. Stud., 25(3):1161-1166.

Sonawance, BR (1995). Chemical contaminants in human milk: an overview. Environ. Health Perspect. 103(6):197-205.

Thompson, JJ; Pacquette, LH (2015). J. AOAC Int. 98: 1702-1710.

World Health Organisation (WHO), (1998). Health Criteria other supporting information in: Guideline for drinking water quality, 2(1) Geneva, 31-388. 